\title{
Analysis on the Relationship Between Investors and Stock Market Volatility Based on Behavioral Finance
}

\author{
Jiehui Li \\ College of Finance \\ Fujian Jiangxia University \\ Fuzhou, China 350108
}

\author{
Qiangwen Zeng \\ College of Finance \\ Fujian Jiangxia University \\ Fuzhou, China 350108
}

\begin{abstract}
Nowadays, securities investment has become one of the important channels for Chinese household asset allocation. However, there are still many shortcomings in China's securities market. Therefore, the traditional "rational person hypothesis" is difficult to be established in the market. At this time, behavioral finance proposes that there is a herd effect in the process of securities trading in China. This paper in 2007-2008, 2014-2015 Shanghai 180 index as the data source, return the CSAD (cross sectional absolute deviation method to empirical study to test this idea, draw the conclusion: China's a-share market and the irrational factors in the process of this factor would lead investors to trade the enormous losses. Through the analysis of retail investors, institutional investors and securities market, the reasons for the irrational sheep flock effect in China's a-share market are followed by corresponding solutions from various aspects. Finally, this paper hopes to gradually guide the whole market to adhere to the value investment concept through various means.
\end{abstract}

Keywords-CSAD; rational man; behavioral finance; herd behavior

\section{INTRODUCTION}

Review the stock market in China in 2015. The stock price index went all the way up to more than 5100 points, but investors were not aware of the potential crisis and even said that the index would reach more than 10, 000. However, after a brief tug-of-war around June, the index staged a roller-coaster thriller, rapidly falling from more than 5100 to more than 3300 , a speed and magnitude that is really rare in history. Through comprehensive analysis, it is found that herd behavior (also called herding effect, which refers to the individual adopting the attitude or behavior characteristic of following the masses under the pressure of the group) undoubtedly contributes to the change.

\section{LITERATURE REVIEWED}

\section{A. Research Status in Foreign Countries}

As far back as 1929, foreign researchers have long dabbled in the existence of herding effect in the stock market. There are two methods to verify herding effect at home and abroad. The first approach focuses on specific investors, For example, the existence of this phenomenon can be tested through the decision preference of fund managers, In 1992, Lakonishok,
Shleifer and Vishy proposed the method of LSV (named after the initials of the three authors) to test the existence of this phenomenon. However, since the stock market in China is dominated by small and medium-sized investors, it may be impractical to use this model to test the herding effect in China's A-share market. Then Werners, Lin and Swanson improved this method to study the existence of herding effect in different stock markets. This method first determines the degree of stock price dispersion as a measure, and then comprehensively analyzes the return on assets in order to study the herding effect of the market as a whole. In the study of herding, many experts and scholars have built a series of models. For example, the cross section return standard deviation model (CSSD) proposed by Christie and Huang (1990), namely Ch method, experts such as Chang and Cheng (1995), have established the absolute deviation model of cross section return rate (CSAD), that is, CCK method. But compared with the CSSD model, the CSAD model has the following advantages: 1. CSAD model is the result of CSSD model development and perfection. Because CSAD abandons the choice of fictitious variables as dependent variables in CSSD model and uses deviations and market returns instead, the abundant data provide more reliable support for empirical analysis. 2. CSAD adds quadratic terms and extends the regression equation. 3. The CSAD model is based on the CAPM model of rational hypothesis. Once the empirical results reject the original hypothesis, it shows that there are irrational factors in the market.

\section{B. Domestic Research Status}

Domestic scholars mostly use foreign models to study herding in securities market. Mei Guoping and Nie Hui (2009) conducted an empirical test on more than 1692 stocks in the Shanghai market from January 4, 2002 to February 31, 2008. The results show that the influence of rational herding on the market is significantly greater than that of irrational herding. That is, the magnitude of impact effect on Shanghai stock market is asymmetrical, which is a good fit with reality. In 2004, Cheng Ximing and others revised Ch model and constructed arch model to measure herding effect in stock market. They collected empirical analysis of stock indices in Shanghai and Shenzhen from 1997 to 2002. The results show that herding effect exists significantly in most of the study plates. Although the above-mentioned scholars have shown through their research that there does exist a certain herding 
effect in China's securities market, the main reasons for this phenomenon are the late start of the Chinese securities market and the imperfect trading mechanism of the market. The overall quality of investors is on the low side, and the investment ideas are not mature. However, in recent years, China's securities market has developed rapidly, continuously improved the market laws, actively introduced various kinds of financial derivatives supply market, and the investors' investment ideas have quietly changed. Therefore, the previous research conclusions cannot fully confirm whether there is still this irrational phenomenon in China's securities market.

On the basis of the above analysis, foreign scholars have created the theoretical basis of herding effect and constructed a series of models, and domestic scholars have generally adopted CSSD or CSAD model to obtain the existence of herding effect in China's securities market. Although most of the above scholars show that the herding effect exists in China's securities market, but with the continuous development of China's securities market, is there still herding effect in China's securities market? On the other hand, considering CSSD has a series of limitations in the choice of methods, this paper uses the latest data in recent years and CSAD model empirical research to test the conclusions of domestic scholars. The research on this issue is not only helpful for the securities regulatory agencies in China to play a certain reference role in the formulation of relevant systems, but also serves as a warning to investors to guard against the bubble risk caused by the accumulation of irrational factors in the stock market.

\section{CSAD MODEL CONSTRUCTION}

\section{A. Model Theory Foundation}

William believes that if there is herding in financial markets, most individual investors tend to agree, and based on this, he defines herd behavior measures as a decentralized indicator of yield. That is, the return rate of stock $i$ and the standard deviation of average return rate of market portfolio, the price tend to be consistent when the whole market appears herd behavior, the standard deviation converges to 0 , that is, the decentralized index is smaller, the standard deviation is larger than 0 , and the decentralized index is larger. Therefore, this paper uses CSAD method to study Shanghai Stock Exchange 180 from 2007 to 2008 and 2014 to 2015 to further test whether herding exists in China's A-share market.

The CSAD computational formula is as follows :

$$
\mathrm{CSAD}=\frac{1}{N} \sum_{i=1}^{N}|R i-R m|
$$

In the above formula, Ri denotes the yield of stock I for a certain period of time, while $\mathrm{Rm}$ represents the market average yield for the same period. Absolute deviation is used to measure the deviation of stock I from the market average yield. The CSAD raw model is represented as follows:

$$
C S A D=\beta 0+\beta 1 R m+\gamma
$$

According to the above formula, assuming the existence of herding effect, it shows that investors generally follow the market average yield, and the difference between the stock yield and the market average return is reduced, that is, the calculated CSAD value decreases. Therefore, the regression coefficient $\beta 1$ is negative; on the contrary, the decentralized index is positively correlated with the market yield. According to the capital asset pricing model, the following is proved :

$$
E(R i)=R f+E(R m-R f) \beta i \text {, the market risk }
$$
coefficient is:

$$
\beta \mathrm{m}=\frac{1}{N} \sum_{i=1}^{n} \beta i
$$

Represents the absolute value of the deviation between the stock I and the market rate of return, the calculation steps are as follows:

$$
\begin{aligned}
& A V D i=|E(R i)-E(R m)| \\
= & |R f+E(R m-R f) \beta i-R f-E(R m-R f)| \beta m \\
= & |\beta i-\beta m||E(R m-R f)| \\
& \text { Therefore, } E(C S A D)=A V D i t=|\beta i-\beta M| .
\end{aligned}
$$

First order derivation for market rate of return, get :

$$
\frac{\partial E C S A D}{\partial|E(R m t)|}=\frac{1}{N} \sum_{i=1}^{n}|\beta i-\beta m|>0
$$

Second order derivation of E (CSAD) to Market rate of return, get:

$$
\frac{\partial^{2} E C S A D}{\partial|E(R m t)|^{2}}
$$

The above formula shows that when there is herd effect in the market, the original hypothesis is rejected, that is, there are irrational factors in the market. However, if we look at the stock market in our country, we can see that the premise and hypothesis of the establishment of rational CAPM model is still not sufficient, which indicates that the single factor linear regression is weak in explaining the securities market of our country. Therefore, in the regression equation, even if the coefficient $\beta_{-} 1$ is significantly positive, the existence of herding cannot be denied. So we must expand CSAD model and use multifactor regression equation to further test herding effect. That is :

$$
\text { CSADt }=\beta 0+\beta 1|R m|+\beta 2|R m|+\varepsilon
$$

The above formula shows that when there is herding effect in the market, the individual investors' decision-making behavior is similar to that of the market masses. In the regression equation, the deviation degree of stock return (CSAD) is negatively correlated with the market return ( $\beta 1$ is negative) or the decrease in the variation of the deviation degree ( $\beta 2$ is negative). In short, as long as the herding effect exists in the market, there is a negative correlation between $\mathrm{Rm}$ and the deviation degree of the sample rate of return, or a decreasing trend of CSAD value. However, when $\beta 1$ and $\beta 2$ 
are negative at the same time, there is a strong herding effect in the market.

\section{B. The Establishment of the Model}

In the course of empirical study on herding effect in Chinese A-share market, this paper mainly bases on the absolute deviation model of cross section proposed by Ajay Khorana (1998), Joseph W. Cheng and Eric C. Chang. About the rate of return index, this paper deals with logarithm.

Since CSAD is based on rational capital asset pricing model, once the empirical results reject the original hypothesis, it will accept the irrational factors in the market. On the other hand, the market rate of return $(\mathrm{Rm})$ is calculated by the weighted market rate of return, the proportion of the market value of each sample stock to the total market value of the sample is taken as the weight. That is:

$$
\mathrm{R}_{\mathrm{m}}=\frac{1}{\mathrm{~N}} \sum_{\mathrm{i}=1}^{\mathrm{n}} \alpha_{\mathrm{i}} \mathrm{R}_{\mathrm{i}},
$$

Where,

$$
\alpha_{i}=\frac{M V_{i}}{\sum_{i=1}^{n} M V_{i}}, \quad \sum_{i=1}^{n} \alpha_{i}=1
$$

It is worth noting that in China's stock market, there is often a "small company effect"-stocks with small circulating capital and low market value usually have higher returns. The stock uses the weight to calculate the market rate of return. At the same time, the degree of activity and volatility of stock trading is an indicator that investors pay more attention to. Amplitude is usually an indicator of market volatility; while the degree of trading activity reflects the sentiment of many parties investors and empty parties investors, this indicator is used as an explanatory variable, that is to say, according to SSE 180 index, the index's amplitude and turnover rate are calculated. The calculation formula is as follows:

Ceiling price-bottom price

Ampli $=\frac{}{\text { Closing price }}$

Daily turnover

Turn $=$

Daily circulation market value
So, the following is the final regression equation in this paper :

$$
C S A D t=\beta 0+\beta 1|R m|^{2}+\alpha a m l i+\gamma t u r n+\varepsilon
$$

\section{EMPIRICAL STUDY}

\section{A. Selection of Sample Data}

In 2008, the global financial crisis, stock markets in various countries suffered a sharp decline; in 2014-2015 a rapid bull market triggered a large number of investors crazy into the stock market. With the deepening of the concept of serving the real economy in China undefined stock market, and the development of the stock market gradually in line with the international market, the investment concept of small and medium-sized investors has been changing from irrational speculative behavior to value investment. Therefore, the author thinks that the investment style has quietly changed in China's stock market, no matter whether it is legal norm or investment logic, but whether the herd effect of the past can be reduced with the general improvement of the investors' investment quality? This is open to question. So the sample time span chosen in this paper is from January 25, 2008 to November 7, 2008 and July 25, 2014 to June 12, 2015 (on the one hand, because of the unusual volatility of the stock market, herding effect is easy to capture, and the 2008 financial crisis caused the global securities market and the blind involvement of domestic and foreign funds in the domestic securities market in 2005, which caused the rapid rise of Chinese stock market. On the other hand, this paper wants to study whether the herding effect has symmetry in the process of rising and falling, so we choose the above time interval to compare and study). At the same time, in order to ensure the consistency of the research conclusions, the sample stocks are listed before 2008 and are still in normal trading. In addition, this paper will choose the market value ratio of sample stock circulation on November 7 , 2008 and June 12, 2015 as the unified weight. This paper uses Eviews 8.0 as the statistical analysis software to carry on regression analysis to the model.

\section{B. Descriptive Statistics}

According to the formula of stock yield, amplitude and turnover rate in the regression equation, the data values of each index are calculated respectively, descriptive statistics are

\begin{tabular}{|c|c|c|c|c|c|c|c|c|}
\hline Weigh & ng CSAD & Isobar CSAD & Weighting Rm & Isobar Rm & Weighting A & Isobar A & Weighting T & Isobar $\mathbf{T}$ \\
\hline Sample number & 216 & 216 & 216 & 216 & 216 & 216 & 216 & 216 \\
\hline Mean value & 0.0131 & 0.0161 & 0.0036 & 0.0039 & 3.8643 & 3.6633 & 1.7306 & 1.93 \\
\hline Median & 0.0112 & 0.0139 & 0.00009 & 0.002 & 3.4626 & 3.287 & 1.6731 & 1.90 \\
\hline Maximum value & 0.0598 & 0.0934 & 0.0640 & 0.0504 & 12.2697 & 12.377 & 4.6071 & 5.68 \\
\hline Minimum value & 0.0028 & 0.0033 & -0.0919 & -0.0854 & 1.2689 & 1.0322 & 0.3638 & 0.32 \\
\hline Standard deviation & 0.0085 & 0.0098 & 0.0209 & 0.01 & 1.8391 & 1.9238 & 0.09020 & 1.15 \\
\hline
\end{tabular}
shown in "Table I":

TABLE I. DESCRIPTIVE STATISTICS OF VARIABLE INDICATORS 2014/7/25 -- 2015/6/1 
TABLE II. 2008/1/25 - A DESCRIPTION OF THE STATISTICAL 2008/11/7 VARIABLE INDICATORS

\begin{tabular}{|c|c|c|c|c|c|c|c|c|}
\hline \multicolumn{2}{|c|}{ Weighting CSAD } & Isobar CSAD & Weighting Rm & Isobar Rm & Weighting A & Isobar A & Weighting T & Isobar $\mathbf{T}$ \\
\hline Sample number & 191 & 191 & 191 & 191 & 191 & 191 & 191 & 191 \\
\hline Mean value & 0.0192 & 0.0225 & -0.0035 & -0.0048 & 5.2368 & 5.5340 & 0.9961 & 1.64 \\
\hline Median & 0.0158 & 0.0197 & -0.0052 & -0.0060 & 4.9424 & 5.1981 & 0.9328 & 1.55 \\
\hline Minimum value & 0.0031 & 0.0081 & -0.0847 & -0.0844 & 1.7683 & 2.0313 & 0.3340 & 0.69 \\
\hline Standard deviation & 0.0303 & 0.0236 & 0.0359 & 0.0339 & 1.7682 & 1.6917 & 0.4533 & 0.63 \\
\hline
\end{tabular}

\section{Empirical Regression}

In this paper, CSAD is used as a direct index to test herding effect. In order to observe the relationship between CSAD and Rm more intuitively, the relationship between CSAD and Rm is drawn in Eviews as follows:

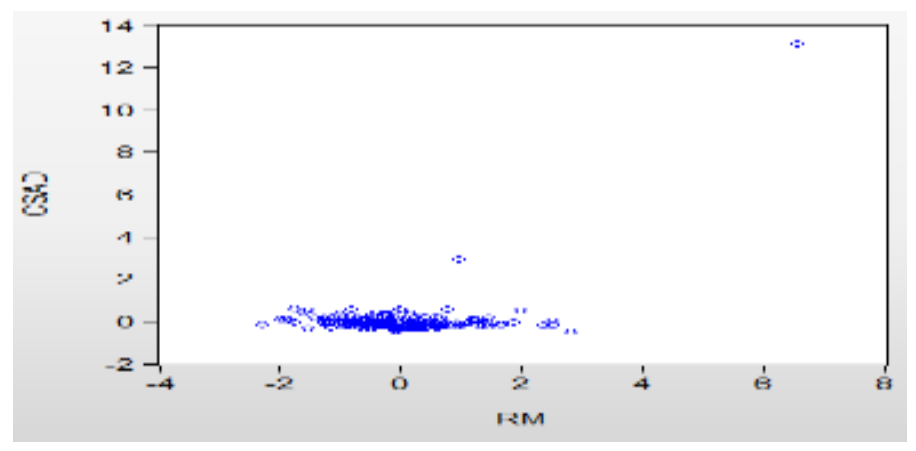

Fig. 1. Relationship between CSAD and Rm 2008/1/25-2008/11/7.

From "Fig. 1", we can see that there is no obvious linear relationship between $\mathrm{Rm}$ and CSAD, but after excluding a few extreme values, the CSAD concentration is near zero with the increase of $\mathrm{Rm}$, that is, the deviation between the market yield and the stock yield decreases with the absolute increase of the market yield.

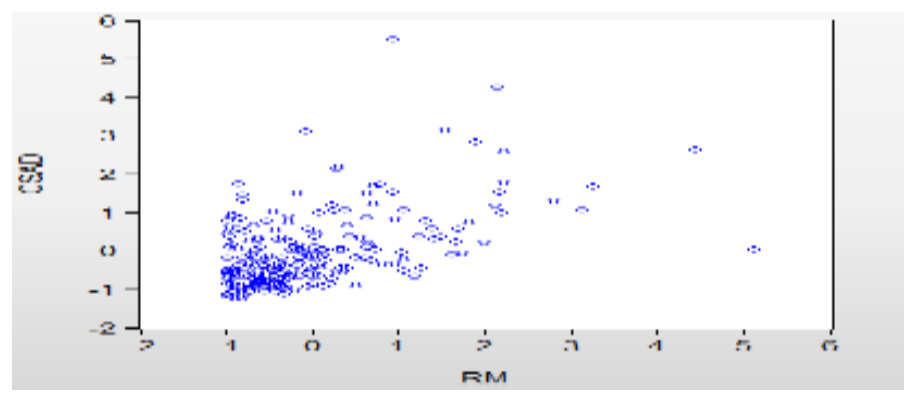

Fig. 2. Relationship between CSAD and Rm 2014/7/25_-2015/6.

Similarly, "Fig. 2" shows that there is no obvious linear relationship between CSAD and Rm. After neglecting the extremes, with the increase of $\mathrm{Rm}, \mathrm{CSAD}$ is roughly distributed between -1 and 1. "Fig. 1" and "Fig. 2" can almost come to a consistent conclusion: the difference between market returns and stock returns is reduced with the absolute increase of stock return. But it is clear that 2008 has more obvious characteristics than 2014- 2015.
TABLE III. REGRESSION RESUlTS OF SAMPLE STOCK FROM JULY 25, 2014 TO JUNE 12,2015

\begin{tabular}{lcccc}
\hline Variable & Coeffient & Std.Error & t-Statistic & Prob. \\
\hline $\mathrm{C}$ & -0.00341 & 0.000952 & -0.358686 & 0.7202 \\
$|\mathrm{Rm}|$ & 0.140744 & 0.063760 & 0.0284 & 0.0284 \\
$\mathrm{Rm} 2$ & -0.952816 & 0.953755 & -0.999016 & 0.3189 \\
$\mathrm{~A}$ & 0.001853 & 0.000865 & 4.012740 & 0.0001 \\
$\mathrm{~T}$ & 0.002662 & 0.000865 & 3.076302 & 0.0024 \\
R-squared & 0.578367 & Duribin-Wason stat & 1.438361 \\
Adjusted R-squared & 0.570374 & & \\
F-statistic & 72.35878 & & \\
Prob(F-statistic) & 0.000000 & & \\
\hline
\end{tabular}

Using the results of Eviews analysis, we can see that $\beta 1$ $=0.140744, \beta 2=-0.952816$, which indicates that the deviation of individual stock returns decreases with the increase of market yield $\mathrm{R}$ m. It is concluded that herding effect does exist in A-shares of China. Observe $\mathrm{P}$ value of $\mathrm{t}$ in four variables of $\mathrm{Rm} 2, \mathrm{~A},|\mathrm{Rm}|$, T. Only $\mathrm{Rm} 2$ could not pass at the significant level of 0.05 , which indicated that $\mathrm{Rm}$ - 2 could not explain the explained variables. The following further observation shows that the model is significant. Next, we further observe the adjoint $\mathrm{P}=0.0000<0.05$ of $\mathrm{F}$ statistics, which shows that the model is significant. Rsquared $=0.578367$, R-squared is a determinable coefficient. From Table III, the explanatory variable "yield, amplitude, turnover rate" is weak in explaining the absolute deviation of the cross-section of the explained variable, which is only half of the explanation.

TABLE IV. SAMPLED STOCKS REGRESSION RESULTS FROM 2008/1/25-1 TO $2008 / 11 / 7$

\begin{tabular}{lcccc}
\hline Variable & Coeffient & Std.Error & t-Statistic & Prob. \\
\hline $\mathrm{C}$ & -0.009429 & 0.002410 & 3.911866 & 0.0001 \\
$|\mathrm{Rm}|$ & -0.708831 & 0.059193 & -11.97486 & 0.0000 \\
$\mathrm{Rm} 2$ & 9.834287 & 0.335716 & 29.29344 & 0.0000 \\
$\mathrm{~A}$ & 0.001107 & 0.000504 & 2.195098 & 0.294 \\
$\mathrm{~T}$ & 0.00948 & 0.00182 & 5.183613 & 0.0000 \\
R-squared & 0.891141 & Duribin-Wason stat & 2.013808 \\
Adjusted R-squared & 0.888880 & & \\
F-statistic & 280.6585 & & \\
Prob(F-statistic) & 0.000000 & & \\
\hline
\end{tabular}

The coefficients $\beta 1=-0.708831$ and $\beta 2=9.834287$ in "Table IV" are also found to be consistent with those of 2014 and 2015. Observing the corresponding $\mathrm{P}$ value of the $t$ value, all the four parameter variables pass the test at the significant level of 0.05 , which shows that the explanatory variable almost makes reasonable explanation to the explained variable. For the statistical value $\mathrm{F}$, the accompanying $\mathrm{P}=0.0000<0.05$, which indicates that the model is significant. R-squared $=0$. 
891141, which show that the goodness of fit of the model is good, and the explanatory variables explain the model more fully. The study of the model is of significance

In a word, the results of the above regression show that, whether the bear market in 2008 or the bull market in the second half of 2014 to the first half of 2015, the A-share market in China has a certain degree of herding effect. But it is clear that the fall in the performance of the herd effect is stronger than the rising market.

\section{ANALYSIS OF HERding EFFECT IN A-SHARE MARKET OF CHINA}

\section{A. Individual Investor}

1) Asymmetric information, high access cost: In the Ashare market, the vast majority of small and medium-sized retail investors have not received professional investment knowledge, and are often caught in the shadows and blindly huddled in the stock market; even if the rational investors are based on the original intention of investing in value, But when weighing the opportunity cost of getting a truly valuable investment target, you end up abandoning the original idea and choosing to follow the flow. The above analysis is the main reason for the formation of herding effect.

2) Weak knowledge base and lack of risk management: The above mentioned shares of small and medium-sized retail investors, a large number do not have the relevant financial knowledge, but also do not see the huge potential risks in the market. This may lead to the stock macro-micro-analysis is not in place, also did not consider stop out. Compared with institutional investors, they all have professional technical researchers and rich experience. As a result, individual investors tend to follow these technicians when it is difficult to decide when the market is volatile. Here institutions will become market leaders, individual investors will be followers.

\section{B. Institutional Investor}

1) Fund managers protect their reputation: At present, Chinese fund companies have open funds and closed-end funds, although open-end funds are not affected by factors such as scale, closure time, etc. But it is its flexibility that makes open-end funds face more redemption pressure than closed-end funds in the process of management and operation. In a bull market, fund companies generally get rich returns; but once the bear market comes, the stock market falls, fund companies generally get lower or even negative yields, and investors make higher returns in order to make money. The open-end fund manager will generally face the pressure of redemption, because the emotion is infectious, once this emotion spreads in the market, the fund manager will even face the risk of leaving, and more importantly, it will affect his reputation. It will be difficult to engage in related industries in the future. Therefore, fund managers generally adopt a conservative approach: to follow the investment strategy of other fund managers and choose similar investment targets, that is, the so-called "The law does not punish numerous offenders", when this behavior becomes a common practice among managers, the earnings of various fund companies are almost the same, investors have no choice but to continue to trust their own fund managers, this is the so-called "hug and keep warm".

2) The investment idea is immature, paying too much attention to the short-term income: Similarly, major investment companies and small investors, make too much emphasis on short-term investment, ignoring value investment. Because the value investment takes a long time, requires the investment personnel to have the long-term, accurate vision. Secondly, in order to meet the goal of realizing short-term returns for investors, many institutions often pile up a few stocks and hype the subject matter, laying "mines" and "wanton" cutting leeks in the stock market.

3) Collusion of institutions to lure retail investors: On the news, the major stock comments frequently express their views, answer questions and doubts for investors, and some also set up group chat through QQ to forecast the trend of the stock market for their own retail investors and put forward investment suggestions. Once some stock appraisal experts and investment institutions have some kind of interest connection, the retail investors are often victimized, at this time, the stock appraisal experts are like batons directing investors to choose their investment targets according to their own wishes.

\section{Securities Market}

1) The existence of falsehood in public information: In our country's securities market, listed companies deliberately seek information in their financial statements that are conducive to raising stock prices. On the contrary, they take an evasive attitude towards the information about bad stock prices. Such as Water deer island this stock in 2014 and 2018 through the same lies twice deceiving investors. When the stock price fluctuates greatly, the stock market will spread the so-called inside information, this emotion will make the investors who lack the rational analysis to rush, form the huge herd effect.

2) Lack of shorting mechanism: Before short selling was introduced in China's securities markets, investors made money by buying low and selling high prices, which would eventually push stock prices higher until the bubble burst. Especially in the event of a stock crash, the only way for investors to avoid risk is to sell off their short positions and wait for the next investment opportunity. But when there is a short-selling mechanism in the market, this kind of one-sided rise in the stock price will be noticed by investors. At this time, the existence of the short-selling mechanism can not only enable investors to obtain profits, but also prevent the stock from plummeting. Make the stock price fluctuate around its value in a reasonable range.

3) China's A-share dividend rate is low: In the global stock market, China's dividend rate and rate of dividend distribution are far less than Hong Kong stocks, U.S. stocks and so on, so investors mainly rely on capital gains to earn 
income. In the past, China's stock market did not strictly require listed companies to pay dividends every year, which led to the emergence of a number of "iron roosters" in China's A-share market, for example, Gold Cup cars which was listed in 1992 have never distributed dividend in 25 years, nor have they distributed dividend in the 19 years since the backdoor listing in 2007. There is no doubt that speculation is encouraged. When stock prices rise quickly, they can't wait to follow, lest they lose sight of the last bus, gradually pushing the stock to a high point, or even away from its intrinsic value. These are the main reasons for strengthening herding effect.

\section{RECOMMENDATIONS FOR MEASURES}

\section{A. Raising the Entry Threshold of the Securities Market}

Through the analysis, it is found that the limitation of the participants' knowledge and risk consciousness contributes to the herding effect of the stock market to a certain extent, this situation is not only unfavorable to the investors to achieve the purpose of preservation and appreciation of value, but also leads to the abnormal volatility of the stock market, therefore, it is not conducive to the healthy and stable development of China's economy to curb domestic and foreign investment enthusiasm in China's capital market. Therefore, China's securities supervision and management should raise the threshold for investors to participate in the stock market. For example, customers who open stock accounts must have at least a high school degree, those with a bachelor's degree or above will be able to trade high risk stocks such as startup board. Financial undergraduate or above may participate in the trading of higher risk financial products such as futures. These measures may appropriately reduce the risk of bubbles in the industry.

\section{B. Strict Investigation of Criminal Liability for False Information Disclosure}

Listed companies in order to the reputation of the company, major shareholders in order to protect their interests, often through false financial reports, the release of false good information to entice investors to make their blood without loss. The above behavior plays a direct role in promoting the abnormal volatility of stocks. China's securities regulators must crack down on these illegal acts, increase the criminal costs of such acts, and investigate their criminal liability according to law for the perpetrators who cause serious consequences.

\section{Fostering Value Investment, Encouraging and Guiding the Long-term Mechanism of Dividend Distribution}

In order to really avoid irrational trading factors in the market, on the one hand, it is necessary to legislate that companies with annual surpluses deduct the relevant taxes and fees for the current year, reinvest the required funds, and so on, must carry out a cash dividend, once the company violates the regulations, strictly limit its their participation in refinancing in the secondary market, restricting its merger and reorganization business; etc. On the other hand, prudent investment and selection of stocks with a larger margin of safety are conducive to increasing the long-term confidence of investors, avoiding panic caused by the herd effect.

\section{Perfecting the Evaluation System of the Salary Value of the Institutional Investment Manager}

Since most institutions, investors focus on the short-term earning effect, which forces investment managers to meet investors' demands in the short term and earn profits in order to earn high salaries and earn reputations. This is also a direct cause of short-term speculation, speculation concept in the stock market in endlessly a reason. For this reason, investors must evaluate the performance of investment managers with long-term yield, and evaluate their performance in a comprehensive, fair and objective manner.

\section{E. Vigorously Develop Innovative Products for Avoiding Risks}

In China, persistent development of short-selling mechanisms, such as margin trading, stock options, futures options, and so on are conducive to avoid unilateral price market, in the long game of the market, only to maintain balance to prevent huge fluctuations in stock prices. Finally, the existence of financial risk-averse products can stabilize investor sentiment, increase the choice of investment products, increase the profit effect of Chinese and foreign investors, make more and more domestic and foreign funds flow into the Chinese stock market, and enhance the financing opportunities of superior companies. Finally, improve the mechanism of China's securities market, and promote the healthy and stable development of China's economy.

\section{CONCLUSION}

After building a regression analysis model in Eviews, this paper confirms the existence of the overall herding effect in China A stock market. The results also show that the herding effect in the rising and falling stock market is asymmetric, and the falling market is more significant, which is related to the investor's ability to bear the risk of rising and falling. Therefore, as far as investors are concerned, they should constantly strengthen their ability to obtain and analyze information, judge the investment opportunity accurately, strengthen their beliefs, dare to break through the bondage of herding, and adopt diversification to reduce systemic risk. With regard to the securities market, it is suggested that the Securities Market Regulatory Commission strengthen the supervision of information disclosure of listed companies, which is conducive to the realization of an open and transparent information transmission mechanism; finally, it should strengthen the efforts to guide investors to change their investment ideas. At the same time, learn from the experience of the development of mature capital market, and strengthen the integration of our market with the international mature market.

\section{REFERENCES}

[1] Lu Jianqing.Behavioral finance[M].Beijing: Tsinghua University Press, 2016. 
[2] Dai Shugeng, Lu Bin.Empirical Analysis of Herd effect in Stock Market based on CSAD Model [J]. Research on Generalized Virtual economy,2016,(01);77-89.

[3] Wu Huan. An empirical study on herding effect in China's A-share Market [D].Lanzhou University,2015.

[4] Wang Chao, Xiu Changbo. An empirical study on herding effect in Shenzhen A-share Market [J]. Modern commerce, 2017(34):182-186.

[5] Chen Hao. Empirical study on herd behavior of institutional investors in Chinese stock market [J]. Research on Nankai economy, 2004(2):91-94.

[6] Cheng Ximing, Jiang Xuelei, Chen Min,etc. An empirical study on the herd effect of Chinese stock market plate[J]. Theory and practice of system Engineering, 2004, 24(12):34-38.

[7] Zhang Yuming, Liu Fengjuan.The internal causes and prevention of "herd effect" [J]. Hunan social science, 2005(3):77-79.

[8] Mei Guoping, Nie Gaohui. Symmetry test analysis of herding behavior in China's stock market [J]. Jiangxi social science, 2009(10):79-82.

[9] Liu Xin. My opinion on herding effect in Chinese Stock Market [J]. Chinese securities and futures, 2010(10):19-19.

[10] Sun Jianquan, Chen Xiaolong. A Comparative study of herding effect between A and B shares in Shanghai Stock Exchange [J]. Journal of Shandong University of Finance and Economics, 2011(5):34-40.

[11] Shen Xiaoru, Lu Hengzhen, Li Xiaozhong. Comparative Analysis of herding effect in Chinese Stock Market [J]. Contemporary economy, 2013(15):108-110.

[12] Wang Jing. Whether there is herding effect in China's Stock Market? - an empirical Test based on the Shanghai Stock Exchange 50 Index [J] Jianghuai forum, 2014.

[13] Christie W G, Huang R D. Following the Pied Piper: Do Individual Returns Herd around the Market?[J]. Financial Analysts Journal, 1995, 51(4):31-37.

[14] Sayim M, Rahman H. The relationship between individual investor sentiment, stock return and volatility [J]. International Journal of Emerging Markets, 2015, 10(3):504-520.

[15] Jr E M S. Stock prices and the Wall Street weather [J]. American Economic Review, 1993, 83(3):págs. 1337-1345.

[16] Statman M. Investor Sentiment and Stock Returns [J]. Financial Analysts Journal, 2000, 56(2):16-23.

[17] Firth M, Wang K, Wong S M. Corporate Transparency and the Impact of Investor Sentiment on Stock Prices [J]. Social Science Electronic Publishing, 2015, 61(7):1630-1647.

[18] Fama E F, French K R. A five-factor asset pricing model [J]. Journal of Financial Economics, 2014, 116(1):1-22.

[19] Brown G W, Cliff M T. Investor sentiment and the near-term stock market[J]. Journal of Empirical Finance, 2004, 11(1):1-27. 